\section{Acknowledgement}

We thank Dr. W. A. A. Wijesiri, Dr. S. U. Kannangara and Dr. Y. V. A. L. Saman Kumara for their support to carry out this study.

\section{References}

1. Nanda K, Peloggia A, Grimes D, Lopez L, Nanda G. Expectant care versus surgical treatment for miscarriage. Cochrane Database of Systematic Reviews 2006. Issue 2 (accessed: 01 September 2008).

2. Molnar AM, Oliver LM, Geyman JP. Patient preferences for management of the first trimester incomplete spontaneous abortion. Journal of the American Board of Family Medicine 2000; 13: 333-7.

3. Sagili H, Divers M. Modern management of miscarriage. The Obstetrician and Gynaecologist 2007; 9: 102-8.

4. Trinder J, Brocklehurst P, Porter R, Read M, Vyas S, Smith L. Management of miscarriage: expectant, medical, or surgical? Results of randomised controlled trial (miscarriage treatment (MIST) trial). British Medical Journal 2006; 332: 1235-40.

5. Forna F, Gulmezoglu AM. Surgical procedures to evacuate incomplete miscarriage. Cochrane Database of Systematic Reviews 2007, Issue 4 (accessed: 01 September 2008).

6. Weeks A. Expectant care versus surgical treatment for miscarriage: RHL Commentary (last revised 15 December 2006). The WHO Reproductive Health Library. Geneva. World Health Organization.

7. Royal College of Obstetricians and Gynaecologists. The management of early pregnancy loss. Green-top Guideline
Royal College of Obstetricians and Gynaecologists, London 2006; 25 .

8. Wieringa-de Waard M, Hartman E, Ankum WM, Reitsma J, Bindels PJE, Bonsel GK. Expectant management vs surgical evacuation in first trimester miscarriage: health related quality of life in randomised and nonrandomized patients. Human Reproduction 2002; 17: 1638-42.

9. Luisse C, Jermy K, May Luise C, Jermy K, May C, Costello G, Collins WP, Bourne TH. Outcome of expectant management of spontaneous first trimester miscarriage: observational study. British Medical Journal 2002; 324: 873-5.

10. Wieringa-de Waard M, Ankum WM, Bonsel GJ, Vos J, Biewenga P, Bindels PJE. The natural course of spontaneous miscarriage: analysis of signs and symptoms in 188 expectantly managed women. British Journal of General Practice 2003; 53: 704-8.

11. Butler C, Kelsberg G, St Anna L, Crawford P. Clinical inquiries. How long is expectant management safe in firsttrimester miscarriage? Journal of Family Practice 2005; 54: 889-90.

12. Wickramasinghe WUS. Surgical treatment versus expectant care in the management of incomplete miscarriage. Thesis for MD Obstetrics and Gynaecology 2010. Postgraduate Institute of Medicine, University of Colombo, Sri Lanka.

13. Wijesinghe PS, Padumadasa GS, Palihawadana TS, Marleen FS. A trial of expectant management in incomplete miscarriage. Ceylon Medical Journal 2011; 56: 10-3.

14. Daly L, Bourke GJ. Estimating single proportion or percentage. In: Interpretation of Medical Statistics. Blackwell Science Ltd, London, 2000; 7: 274.

\title{
A qualitative study on patients' perceptions of expectant management of first trimester incomplete miscarriage
}

\author{
P S Wijesinghe ${ }^{1}$, R P Herath ${ }^{1}$, I D H P K Abeysundara ${ }^{1}$
}

(Index words: incomplete miscarriage, qualitative research, expectant management)

\begin{abstract}
Introduction Efficacy and safety of expectant management of first trimester miscarriage are well known, though the patients' perceptions and attitudes are less clear. This study was designed to understand the women's perception of symptoms, acceptability, fertility wishes and care received.
\end{abstract}

Methods A qualitative study among 25 women who were allocated to the expectant management arm of a randomised control trial, which compared expectant versus surgical management of incomplete miscarriage, was carried out. Interviews were recorded at the end of two weeks from the initial diagnosis based on five themes, which were transcribed and analysed.

${ }^{1}$ Department of Obstetrics and Gynaecology, Faculty of Medicine, University of Kelaniya, Sri Lanka.

Correspondence: PSW, e-mail: <prasanthaw@gmail.com>. Received 2 December 2011 and revised version accepted 26 June 2012. Competing interests: none declared 
Results Out of the 25 interviewed, two had to undergo surgical evacuation due to failed expectant management. Excessive bleeding was the main concern especially for employed women. Ideas and beliefs of family members influenced the women's experience. Majority preferred expectant management in a possible future event. Many expected to conceive again but preferred to delay a pregnancy even in the absence of any contraindications. Inadequate knowledge of expectant management led to dissatisfaction regarding the care received.

Conclusions Better understanding on the natural course of events in spontaneous miscarriage will help not only the patient but also the relatives in accepting expectant management of first trimester miscarriage and influence their ideas, beliefs and feelings. Improved health education, counselling, and symptomatic relief are important aspects in improving the overall quality of care.

Ceylon Medical Journal 2012; 57: 145-149

\section{Introduction}

Miscarriage is common, affecting around one in six pregnancies [1]. It is a distressing experience for women and their partners. Surgical evacuation of the uterus has been the conventional treatment of miscarriage [2]. This mode of management has changed with the development of more refined diagnostic techniques and invention of alternative therapeutic interventions [3]. Recently the possibility of conservative management has been tried and tested. Expectant management is an effective and safe alternative to surgical evacuation for incomplete miscarriage before 14 weeks of amenorrhoea confirmed by ultrasound with retained products of $15-50 \mathrm{~mm}$ in the maximum antero-posterior diameter of the endometrial cavity [4].

Studies exploring the consequences of early miscarriage have shown an increased incidence of grief, anxiety, depression, stress, guilt, self-blame, relationship problems and even suicide among sufferers [5]. Most of the studies done on these issues were quantitative in nature, involving the application of a range of standardised scales and health measures. An area that has not been adequately studied is the patients' experiences with different modes of management.

The knowledge of the patients' perceptions of expectant management enables the health care worker to provide quality care. Therefore, we need more information about physical and emotional experiences of spontaneous abortions in order to counsel the patients. There are few qualitative studies which have discussed this issue, but none has been conducted in Sri Lanka $[6,7]$.

\section{Methods}

A randomised clinical trial conducted in the University Gynaecology Unit of the North Colombo Teaching Hospital, Ragama, evaluated the efficacy and safety of expectant versus surgical management of incomplete miscarriage before 14 weeks of amenorrhoea with ultrasound evidence of retained products of conception of 15-50 $\mathrm{mm}$ in the antero-posterior diameter. Expectant management involved in-ward treatment until resolution of heavy bleeding and pain. At the end of two weeks, maximum antero-posterior diameter of the retained products of conception was measured and a diameter less than $15 \mathrm{~mm}$ was considered as complete miscarriage. Results of this study were published which concluded that expectant management is an effective and safe alternative to surgical evacuation in the management of first trimester incomplete miscarriage [4].

A qualitative study was carried out among 25 women allocated to the expectant management arm of the above study. At the end of two weeks follow up period after obtaining informed written consent, women were interviewed individually in a separate room with the presence of a female chaperone. The interviews were based on five principal themes (Table 1). An unconditional positive regard of the interviewer towards the patient was adopted. Each interview, which lasted from 60 to 90 minutes, was an autonomous expression of the patient's points of view. All interviews were carried out in Sinhalese and recorded with a digital voice recorder, by one of the authors. Subsequently all the authors listened to the recordings individually and as a team. Transcriptions were prepared based on the recordings. The Language Unit of the Faculty of Medicine, University of Kelaniya, did the translations. Approval was obtained from the Ethical Review Committee of the Faculty of Medicine, Ragama.

\section{Table 1. Principal themes of the interviews}

- Bleeding and pain

- Ideas, beliefs and feelings regarding the intervention

- Patient's preferable treatment method in a future event

- Further fertility wishes

- $\quad$ Perceived care received during the time of admission

\section{Results}

Demographic details of the twenty-five women who were interviewed are presented in Table 2.

Bleeding and pain: Women were very keen to express their ideas regarding these symptoms. In the follow up period, majority of women experienced heavy bleeding and pain, which interfered with their day to day activities. Some important comments made are;

"I felt the same severe pain one feels while having contractions and it kept on getting worse. I bled slightly for about a week. I suffered a lot and got severe cramps. I wish someone offered to remove this somehow."

"It was more painful than periods, excruciatingly painful. The bleeding occurred during this time, and two more large thick blood clots were expelled. I was in the toilet for a long time, as I was bleeding heavily. Gradually the pain subsided as the blood clots passed." 
Table 2. Characteristics of the study population $(n=25)$

\begin{tabular}{|c|c|}
\hline Characteristic & $n$ \\
\hline \multicolumn{2}{|l|}{ Age (years) } \\
\hline $20-25$ & 06 \\
\hline $26-30$ & 10 \\
\hline $31-35$ & 07 \\
\hline $36-40$ & 01 \\
\hline $41-45$ & 01 \\
\hline \multicolumn{2}{|l|}{ Education } \\
\hline $\mathrm{A} / \mathrm{L}$ or higher education & 12 \\
\hline $\mathrm{O} / \mathrm{L}$ & 08 \\
\hline Grade $05-10$ & 04 \\
\hline Grade $01-05$ & 01 \\
\hline \multicolumn{2}{|l|}{ Religion } \\
\hline Catholic & 13 \\
\hline Buddhists & 12 \\
\hline \multicolumn{2}{|l|}{ Occupational status } \\
\hline Employed & 14 \\
\hline Unemployed & 11 \\
\hline \multicolumn{2}{|l|}{ Family system } \\
\hline Nuclear family & 19 \\
\hline Extended family & 06 \\
\hline \multicolumn{2}{|l|}{ Reproductive history } \\
\hline One or more previous successful pregnancy & 15 \\
\hline One or more previous miscarriage & 07 \\
\hline One or more previous still birth & 01 \\
\hline
\end{tabular}

"I started bleeding heavily once I got home. I passed many clots along with blood, and this included one large thick blood clot. It was then that the pain began to slowly subside."

Few women mentioned that the symptoms were tolerable. All of them were unemployed.

"There was no ache, nothing at all. I began to have a bloody discharge.... When they were doing the scan they said that, .... a lot of parts have been expelled. There was slightly more bleeding compared to my menstrual periods. But it was okay."

Ideas, beliefs and feelings regarding the intervention: Most of the participants were satisfied about the mode of management. They preferred expectant management than surgical evacuation.

"I think it is better than performing an operation. There was nothing left inside to remove..."

However, their concerns regarding the method were influenced to a large extent by family members, including husband, mother and mother in law.
"My mother in law said that if I go through surgery, I will undergo miscarriages repeatedly. She also said it will become a habit if performed once."

"What my parents said was that when something like this happens, they usually perform surgery. They believed that I might have to go through the same procedure. Even my husband thought that since I have had a miscarriage I would have to undergo surgery. However, I was told that there was no need to do it after they checked the scan. Therefore, I was happy that I did not have to go through it. ...so it's better this way."

Some women were influenced by fellow patients in the ward.

"A patient was asking whether there is a risk of not conceiving again if she goes through surgery. About two or three people told her that it is so. She was told that if one miscarries for about three-four times and goes through surgery, that person will not be able to conceive again."

Few patients in whom expectant management was not successful did not mention a preferred method that would have been used. However, they expected to get rid of the retained products as quickly as possible.

"It would've been better if some kind of method was used to remove this without wasting time."

Patients' preferred treatment method in a possible future event: Patients' preferred treatment method in a future event is an indirect evidence of satisfaction regarding the mode of management during this admission. Most of women preferred expectant management. all."

"I think this method is suitable. It was painless after

"Everything will be fine as long as it's expelled naturally."

"Actually I don't have much knowledge regarding this matter. I feel this method is better than surgery or pills."

"It's like this, people who talked to me told that they can't get pregnant since they underwent surgery several times. I wish to have a baby soon. I would prefer a less risky method like this."

Some mentioned that they would go for medical management.

"Since we don't know what it is doctor, I'm scared to undergo an operation. As such I feel insertion of pills is better."

Fertility wishes: Majority of the women wished to conceive again. However, they preferred to delay it even there was no medical contraindication.

"We are hoping to have a baby, doctor. But it's not possible as we have to wait for at least three months, isn't it doctor?"

"We are hoping to but not now. I'm still a little bit scared to think about it." 
Few of them completely gave up the hopes of pregnancy.

"Oh my gosh! No way! I don't want babies anymore. I've been through enough."

Perceived care received during the time of admission: Satisfaction regarding the care received during the time of admission was assessed. Most of the patients expected something more tangible.

\section{"I was here for four days, but nothing was done."}

Their main concern was that they were not given any medicine other than analgesics while they were in such a distressing situation.

"I was here for two days. But nothing was given other than two tablets of paracetamol."

"I was a little annoyed. I was here for about twothree days. Apart from two paracetamol tablets, no medicine was given."

\section{Discussion}

Even though patients were told during counselling that the symptoms would be more or less similar to a normal menstrual period, during the follow up period, many said that the symptoms were much worse. Pain was the principal symptom, which troubled them more than the bleeding. The amount of bleeding rarely amounts to emergency admission but is often frightening, and women need reassurance and explanation [7]. Women should be informed that pain and bleeding would subside after the expulsion of the retained products. Moreover, heavy bleeding is predictive of a relatively quick spontaneous expulsion of products of conception [8]. Therefore, the probable bleeding pattern and degree of pain that will be experienced during the follow up period should be explained to the patient at the time of discharge from the ward. Prescribing adequate analgesia to all patients during the follow up period, even though there is no pain at the time of discharge from the ward is important. Symptoms of miscarriage have a greater impact on working women. Therefore, during counselling special emphasis should be made on this aspect.

Most of the participants were satisfied with regard to the treatment modality. Patients were well aware of risks and complications of surgery and preferred spontaneous expulsion of the products. In a miscarriage, there is no major achievement for the patient even though they undergo surgery unlike in a viable pregnancy where they would be rewarded with a live baby. This is a relevant factor in patients' acceptance of expectant management.

However, their concerns regarding the method were greatly influenced by family members. Better counselling should be available not only to the patient but also to family members where appropriate. Men and women respond differently to miscarriage. Likewise, their experiences of grief and depression are different [9]. Therefore, both partners should be educated separately and as a couple. Influence of mother and mother in law is an important factor in our community. Therefore, counseling of mother and mother in law is also important.

In our hospital setting, patients exchange ideas during their stay in hospital, which will have an impact on the patients' perception of her management plan. Therefore, provision of accurate information to each patient is required. If we can achieve this goal, inter-patient communication will become a useful tool in patient education.

The treatment modality of a miscarriage does not affect subsequent pregnancy rates with around four in five women giving birth within five years of the index miscarriage [10]. However, in practice the impact of the mode of management on fertility wishes should be considered. Expectant management is known to cause least psychological problems to the patient [11]. But in our study, most women wanted to delay the next pregnancy, even though there was no medical contraindication for pregnancy. This is likely to be due to societal misconceptions, but may also be due to the psychological impact of the mode of management and care they received. Health professionals should understand the potential effect of the loss and importance of adequate support and care $[7,12]$. During the follow up after a miscarriage women should be informed that they could become pregnant after the next menstrual period if they wish to.

Most of the patients perceived that not enough was done for them during the stay in hospital. The concept involved in the expectant management is awaiting spontaneous expulsion of the products of conception and surveillance for complications; thus requiring only symptomatic relief when necessary. However, patients were unaware of this fact and expected more medications other than analgesics. This was the cause for the dissatisfaction in most. Therefore, patients should be better informed that there is no need for medications except analgesics in this mode of management.

\section{Acknowledgement}

We acknowledge National Science Foundation of Sri Lanka for the financial support through grant number RG/ 2007/HS/07 and Language Unit of the Faculty of Medicine, University of Kelaniya for the assistance provided.

\section{References}

1. Everett C. Incidence and outcome of bleeding before the 20th week of pregnancy: prospective study from general practice. British Medical Journal 1997; 315: 32-4.

2. El-Sayed MM, Mohamed SA, Jones MH. Expectant management of first-trimester miscarriage. Journal of Obstetetrics and Gynaecology 2009; 29: 681-5.

3. Hinshaw K, Fayyad A, Munjuluri P. The management of early pregnancy loss. Green-top Guidelines No. 25, 2006.

4. Wijesinghe PS, Padumadasa GS, Palihawadana TS, Marleen FS. A trial of expectant management in incomplete miscarriage. Ceylon Medical Journal 2011; 56: 10-3

5. Nielsen S, Hahlin M, Möller A, Granberg S. Bereavement, grieving and psychological morbidity after first trimester 
spontaneous abortion: comparing expectant management with surgical evacuation. Human Reproduction 1996; 11: 1767-70.

6. Smith LF. Women's experiences of three early miscarriage management options - a qualitative study. British Journal of General Practice 2006; 56: 198-205.

7. Wiebe E, Janssen P. Conservative management of spontaneous abortions. Women's experiences. Canadian Family Physician 1999; 45: 2355-60.

8. Wieringa-de W M, Ankum WM, Bonsel GJ, Vos J, Biewenga $\mathrm{P}$, Bindels PJE. The natural cause of spontaneous miscarriage: analysis of signs and symptoms in 188 expectantly managed women. British Journal of General Practice 2003; 53: 704-8

9. Swanson KM, Chen HT, Graham C, Wojnar DM, Petras A. Resolution of depression and grief during the first year after miscarriage: a randomised controlled clinical trial of couplesfocused interventions. Journal of Women's Health 2009; 18: 1245-57.

10. Smith LFP, Ewings PD, Quinlan C. Incidence of pregnancy after expectant, medical, or surgical management of spontaneous first trimester miscarriage: long term follow up of miscarriage treatment (MIST) randomised controlled trial. British Medical Journal 2009; 339: b3827.

11. Waard M, Hartman EE, Ankum WM, Reitsma JB, Bindels PJ, Bonsel GJ. Expectant management versus surgical evacuation in first trimester miscarriage: health-related quality of life in randomised and non-randomised patients. Human Reproduction 2002; 17: 1638-42

12. Stirtzinger R, Robinson GE. The psychologic effects of spontaneous abortion. Canadian Medical Association Journal 1989; 140: 799-805

\title{
Correlation of clinical, parasitological and histopathological diagnosis of cutaneous leishmaniasis in an endemic region in Sri Lanka
}

\author{
R R Ranawaka ${ }^{1}$, P H Abeygunasekara ${ }^{2}$, H S Weerakoon ${ }^{1}$ \\ (Index words: L. donovani, cutaneous leishmaniasis, clinical diagnosis, parasitology, Sri Lanka)
}

\begin{abstract}
Introduction Diagnosis of cutaneous leishmaniasis (CL) largely depends on the clinical appearance of the lesions in endemic areas.

Objectives The aim of this study was to correlate the clinical diagnosis with positive laboratory tests used for the identification of leishmania parasite (stained smears and histopathology) and therapeutic response.

Methods 114 clinically suspected patients (190 lesions) were studied. They were diagnosed as typical clinical cases $(87.4 \%)$ and clinically suggestive cases $(12.6 \%)$ on the basis of criteria for clinical diagnosis. Slit-skinsmear and histopathology were performed in all patients.

Results Out of 103 who were clinically diagnosed, 62 $(60.2 \%)$ were confirmed parasitologically. Out of 41 who were negative for both smear and histology, 34 (33\%) had supportive histology and the diagnosis was supported by good treatment response in 37 (35.9\%). Hence, the clinical diagnosis was $93.2 \%$ accurate and this increased to $96 \%$ after observing the good response to therapy.
\end{abstract}

Conclusions Considering the magnitude of the problem, limited resources, and clinical accuracy of $96 \%$, clinical diagnosis by a dermatologist appears to be reliable enough in diagnosing $\mathrm{CL}$ lesions in endemic areas in Sri Lanka.

Ceylon Medical Journal 2012; 57: 149-152

\section{Introduction}

Cutaneous leishmaniasis (CL) is a growing public health problem in several parts of the world, including Sri Lanka [1-4]. The causative organism is identified as Leishmania donovani zymodeme MON-37 [5]. Although occasional cases are reported from all the provinces, Southern and North-Central provinces are endemic reporting more than 1000 cases annually $[2,3]$. The diagnosis of CL largely depends on the clinical appearance, especially in endemic areas. As a general rule in endemic areas of the world any boil that is present for several weeks and does not respond to ordinary therapy should be considered as CL unless proven otherwise [6]. A diagnostic challenge arises when the lesions appear in

Departments of ${ }^{1}$ Dermatology, ${ }^{2}$ Pathology, Teaching Hospital, Anuradhapura, Sri Lanka.

Correspondence: RRR, e-mail: <ranthilaka37@yahoo.com>. Received 23 May and revised version accepted 23 August 2012. Competing interests: none declared. 